Article

\title{
Resistance to Regulation: Failing Sustainability in Product Lifecycles
}

\author{
Mark B. Taylor ${ }^{1, *}$ and Maja van der Velden ${ }^{2}$ (I) \\ 1 Department of Private Law, University of Oslo and Fafo Institute for Labour and Social Research, \\ 0650 Oslo, Norway \\ 2 Department of Informatics, University of Oslo, 0316 Oslo, Norway; majava@ifi.uio.no \\ * Correspondence: mark.taylor@fafo.no
}

Received: 3 October 2019; Accepted: 18 November 2019; Published: 19 November 2019

\begin{abstract}
International policy and law have long sought to ensure that states regulate the negative impacts of production processes on people and the planet. Sustainable Development Goal (SDG) 12 targets sustainable production and consumption; international conventions, such as the Basel Convention, or the Convention on Biological Diversity (CBD), and the International Labour Organisation Conventions, all seek to regulate toxic or labour-related impacts associated with industrial production. However, there is ample evidence that such impacts continue. At a time of increasing pressure to develop sustainable systems of production and consumption, we asked whether the existing legal frameworks are appropriate to the task of regulating for sustainability in consumer products. Drawing on research conducted into sustainability in the mobile phone lifecycle, this paper examines the regulatory ecology of hotspots of unsustainability in the product lifecycle of electronics. This paper finds that the interaction of regulatory disjunctures, business models, design of technology, and marginalisation combine to ensure that our systems of production and consumption are predisposed to resist regulation aimed at sustainability.
\end{abstract}

Keywords: regulation; product lifecycle; electronics; toxicity; labour

\section{Introduction}

Technology is being consumed in ever-greater quantities. In March 2019, there were 5.13 billion unique mobile phone subscribers [1]. Despite signs that the demand for new phones is peaking, consumption levels remain high: it is estimated that 1.48 billion new smart phones were shipped in 2018 [2]. This is in part because phone technology has developed to the point at which smart phones can be tools of use in many different functions in everyday life, as well as the fact that the branding surrounding technological innovation by phone makers encourages customer upgrades to the latest model.

The production processes designed to meet the demand for mobile phones and other electronics have significant impacts on workers and the environment [3]. Technological developments are likely to aggravate these realities. For example, in 2018, a speculative boom in cobalt and lithium supplies for electric vehicle (EV) batteries accompanied expectations of a rise in the demand for electric vehicles, pushing mining into ever more vulnerable areas or aggravating human and eco-toxicity impacts of existing operations [4-6]. The expansion of the internet of things (IoT) and 5G networks will push non-compatible technology out of use, while at the same time creating a new range of IoT products, potentially adding semiconductors, antennas, and batteries to a wide variety of products, such as basketballs, shoes, bike locks, etc. These trends in production and consumption suggest an increasing importance of electronics in many traditionally non-electronic products. 
There is an urgent need to consider the sustainability of the lifecycle of electronics, from natural resource extraction through to the end of life of electronic products. Given the level of electronics consumption, and the development of new technology, particular focus must be placed on the ability of regulation to protect people and the planet from the harms involved in the production and disposal of electronic products. To that end, this article describes the regulatory ecology of unsustainability in the lifecycle of electronics, using the smartphone as a case. By 'regulatory ecology,' we mean the ways in which law, markets, social norms, and architecture-individually and in interaction-create or sustain particular sustainability hotspots. We define hotspots as a lifecycle stage, process or elementary flow, which accounts for a significant proportion a product's impact on a planetary boundary or its social foundation $[3,7]$.

In previous research, we used a standard hotspots analysis [8] to identify three priority sustainability hotspots in the mobile phone lifecycle: biodiversity in the resource extraction phase, precarious work in the manufacturing phase, and eco- and human toxicity in the end-of-life phase [3]. These were not the only risks to, or impacts on, people and the planet detected, but they were those which we were identified as priorities using the hotspots analysis method. Based on this identification of hotspots, we identified the constraints that prevent sustainable production and consumption of mobile phones [9], as the basis for understanding the sources of resistance to regulation in product lifecycles. Our purpose in so doing has been to explore the regulatory dynamics that hinder or enable progress in meeting sustainability targets, such as those under Goal 8 (Economic Growth and Decent Work) and Goal 12 (Sustainable Production and Consumption) of the UN Sustainability Goals. Our findings indicate that traditional approaches to regulation are insufficient. By assuming a simple model of compliance, based on clear standards backed by viable sanctions as a deterrent, policy makers run the risk of significantly under-estimating the regulatory complexity of transnational product lifecycles. Product lifecycles are characterised by regulatory fragmentation (a lack of harmonization of applicable rules across jurisdictions), as well as significant levels of labour informality at key stages of the product lifecycle. These realities demand a different approach. We propose a systemic approach to regulating the product lifecycle, one which assumes these challenges and designs regulation accordingly.

\section{Approach, Definitions, Methods}

For our definition of sustainability, we adopted the planetary boundaries and social foundations framework [10-12] as our sustainability framework. This sustainability framework is consistent with the Sustainable Development Goals (SDGs) [13]. However, while the SDGs are policy targets intended to harmonise goals for states, the planetary boundaries framework presents research-based limits for human impacts on our planet's biosphere. The social foundations are based on research and normative standards for human welfare, including but not limited to human rights. This sustainability framework does not distinguish between states or between economic sectors, but aggregates impacts on the planet and on human society as one system. This makes the framework well suited to considering the sustainability of product lifecycles, which are often the result of transactions between different business entities across multiple jurisdictions.

Accurately assessing the unsustainability of a particular activity, an activity that overshoots the limits of our planet or falls short of realising human welfare, requires defining that activity with sufficient clarity, so that data on actual impacts can be gathered and analysed. For this purpose, we needed to specify the focus of the research (unit of analysis) with sufficient precision, and in a way that made it possible to use empirical data and information about production processes. To this end, we chose the product lifecycle (PLC) as our unit of analysis. By focusing our analysis on the PLC of mobile phones we acknowledge and build upon the analysis of global systems of production based on the concept of global value chains (GVCs). However, traditional GVC analysis does not necessarily take into account social and environmental externalities and impacts which arise at the different stages of production [14]. Nor does it address the end of life of a product: GVC analysis tends to be linear and to assume that the value of a product or service ends with its purchase by a consumer or end 
user. For the purpose of studying the sustainability of products, adopting a product lifecycle approach enabled us to take a perspective informed by GVC analyses and adapt these to include a concern with the social and environmental impacts of the full mobile phone production and consumption process, including the end of life of products. In addition, it enabled an analytical perspective that extends beyond the value chain related to a particular company. The result was a unit of analysis-the PLC - which allowed us to consider the full lifecycle of the product, including both the value and the externalities generated in all phases of the PLC.

The mobile phone was chosen as a case study because it is an Information and Communications Technology (ICT) device in wide and expanding use, in both households and businesses. The mobile phone offered an opportunity to explore the challenges of policy making for a product with a complex, transnational supply chain, involving several different material inputs and processes at each phase of its lifecycle. In this, mobile phones are comparable to other consumer electronics, making it useful as a case study of the challenges of regulating electronics products in general in order to improve the sustainable production and consumption of electronics.

A lifecycle approach enabled us to map the various phases of the mobile phone's life and to identify ways in which its production and consumption generates impacts (social and environmental externalities) at each phase in the mobile phone lifecycle. Focusing on the PLC as our unit of analysis enabled us to look for evidence in the literature about the social and environmental impacts of processes specific to mobile phone production, or more generally to the components of electronics which are common to mobile phones. For data about the impacts of mobile phones on people and planet, we turned to the body of mobile phone Lifecycle Assessment (LCA) literature and other related empirical studies. From this database we were able to identify six phases of the mobile phone PLC: design, resource extraction, manufacturing, transport, use, end of life. For the purposes of this study, we excluded in-depth examination of the use phase, as this would have expanded the scope of the research to such social impacts as privacy, surveillance and network shutdowns, or environmental impacts, such as energy consumption through internet server use. While these impacts are severe and an integral risk posed by mobile phone use, we justified this exclusion on the grounds that this would make the study unworkable by expanding the scope of the research to any potential use of mobile phones. Instead, we focused on the production of mobile phone as a material artefact. A literature review resulted in more than 400 relevant academic articles and reports published by a variety of actors (research institutes, non-governmental organisations, labour unions, and companies). Coding this literature resulted in the identification of 82 different social and environmental impacts [3].

On this basis, we were able to identify impacts in the product lifecycle that transgress the categories set out in the planetary boundary framework. In order to prioritize impacts for our regulatory research, we deployed a method developed by the United Nations Environmental Programme (UNEP)/Society of Environmental and Toxic Chemistry (SETAC) Lifecycle Initiative $[7,8]$. Using the UNEP/SETAC method, we selected three sustainability hotspots in the mobile phone lifecycle for further research: biodiversity in the resource extraction phase, precarious work in the manufacturing phase, and ecoand human toxicity in the end-of-life phase. In short, we were able to identify sustainability hotspots across the full lifecycle of the smart phone and then focus our analysis on particular externalities to better understand the regulatory dynamics at work in perpetuating certain negative impacts on people and the planet arising from the mobile phone lifecycle [9].

The problems of unsustainability in the mobile phone lifecycle are 'wicked problems', problems that cannot be managed by one jurisdiction, organisation, or discipline [15]. Understanding the regulatory dynamics at work in perpetuating wicked problems demands a coherent analytical framework to aid in the research task of understanding the complexity of interactions at work in relevant systems. With this in mind, we opted for an approach we have elsewhere termed 'regulatory ecology' [16,17]. Based on the regulatory theory developed by Lessig [18], we use the concept of regulatory ecology to understand the ways in which law, markets, social norms, and architecture (the material for physical constraints imposed on a subject of regulation) interact to create or sustain particular hotspots. In a 
regulatory ecology, we define law as positive law, rules promulgated (ex ante) and enforced by a state. Social norms are constraints imposed (ex post) through social sanctions imposed by members of a community, although the power of social norms lies in our ability to internalize them so that they guide our decisions before they are made. Markets constrain through price, not least with respect to the principal factors of production, such as labour or natural resource commodities. Unlike law and social norms, the regulatory effect of such market constraints is simultaneous to the activity being regulated. Even where payment for a benefit or resource can be deferred, or where risk is the potential for financial loss in the future, the constraining obligation involved in a market activity is taken on and remains as long as one remains in the market. The final category of constraint, or modality of regulation is architecture, the obvious-and yet widely overlooked-constraints imposed by the physical world. This is a mode of regulation that has to do with materiality, not in the legal sense of having a material (e.g., financial) consequence, but in the sense of emanating from physical matter. Architecture includes naturally occurring phenomena, such as the location of natural resources, or human-built physical constraints, such as the design of electronics.

For the researcher, these modalities of constraint act as categories for organising the research of a complex system. They encourage us to ask questions about the ways that this system encourages respect for a rule or encourages non-compliance. At times, the answers to these questions may be obvious-mining harms biodiversity, informal labour promotes low wages. But a regulatory ecology approach requires that we think about these aspects not as discrete phenomena to be regulated by law, but as factors constraining or enabling the effectiveness of law. By putting these elements together in a system of interactions, it becomes clear that no one constraint can be said to be the single cause of the effectiveness (or otherwise) of the law. Rather, it is the cumulative effect of all of these constraints, as well as the interactions between them, which help create an ecology of regulation: they reinforce or undermine the effectiveness of a rule creating a regulatory ecology around a social phenomenon.

There are several important aspects of this approach. First of all, constraints act both to constrain an actor directly and also indirectly or in interaction with each other. For example, a law supporting gender diversity in the workplace will be more or less effective depending on prevailing social norms about women working outside the home, the wage differentials between men and women in the labour market and the availability of day care [19]. Second, a regulatory ecology analysis is not deterministic. It does not assume that these modes of constraint determine behaviour. It assumes we have agency —or interpretive flexibility—in our ability to interpret and adapt to constraints. This aspect of interpretive flexibility is important in understanding the operation of a regulatory ecology. It is through interpretative flexibility that adaptations arise, including with respect to either compliance or resistance to regulation, for example through avoidance and evasion.

The focus on the regulatory ecologies of particular hotspots is meant to help us manage the complexity of research into regulation of complex systems, like a product lifecycle. In seeking to understand the regulatory ecology of each hotspot, we identified the legal jurisdictions which correspond to the location of the hotspot and identified and collated the applicable legal rules which attempt to regulate the hotspot. We then identified the principal interactions of law with markets, social norms, and architecture, which constrain or prevent the law from being effective in its implementation and enforcement. In short, we deployed the regulatory ecology framework as an aid in our attempts to uncover the obstacles to sustainable product lifecycles. By describing these regulatory ecologies, we hope to identify areas that may be considered as a focus for legal reform proposals.

\section{Results}

In each phase we examined-natural resource extraction, manufacturing, and end of life-we found two principal sources of impacts that threaten people and the planet:

- Toxicity, in particular the vulnerability of ecosystems and people (workers and communities) to hazardous materials; 
- Precarious work, in particular the vulnerability of people arising from forms of non-standard employment relationships and repression of their rights to collective action.

These impacts arise across the mobile phone lifecycle and manifest themselves in different ways, depending on the nature of the activity at issue, i.e., mining of natural resources, assembly of parts or products in factories, or the disassembly or recycling at the end of life of mobile phones. Our analysis found that toxicity and precarious work arise in each of these phases of the mobile phone lifecycle and generate sustainability hotspots. At times, these impacts were found to interact, such as when the impacts of toxicity aggravated labour precarity or when labour precarity prevented workers from organising to address toxicity in the workplace.

For each of the hotspots identified, there are international legal regimes, which establish legal norms requiring the protection of people or the planet from particular harms and establish obligations for states to implement regulation at the national level. In some cases, these protections are provided for under a single treaty regime. For example, the hotspot of precarious work is covered by the core conventions of the International Labour Organisation (ILO), which govern issues such as, freedom of association, forced labour, discrimination, child labour, and occupational health and safety. In other cases, protections are manifested in clusters of applicable international treaty law. For example, impacts arising from toxicity are covered by global frameworks for the protection of biodiversity under the Convention on Biological Diversity (CBD) (1992, entered into force), and as elaborated by Strategic Plan for Biodiversity 2011-2020 and the Aichi Biodiversity Targets. Aichi Target 8 makes specific reference to 'other international processes' dealing with such impacts, such as the Stockholm Convention on Persistent Organic Pollutants (POPs) and the Rotterdam Convention on the Prior Informed Consent Procedure for Certain Hazardous Chemicals and Pesticides in International Trade (1998, entered into force 2004). In 2012, the secretariats of these two conventions, joined under UNEP, along with the Basel Convention on the Control of Transboundary Movements of Hazardous Wastes and Their Disposal.

These are just examples of applicable international law regulation. There is not the space here to describe the full range of protections against toxic impacts against people and the planet or obligations to combat precarious work. Elsewhere, we have provided more detail about these [9]. However, our mapping of the regulatory ecologies of each hotspot showed that there were in fact international and national legal frameworks that address key aspects of the hotspots. These often form the basis for attempts by states to coordinate policy and encourage implementation. For example, the issue of biodiversity was on the agenda of the G7 in April 2019. In 2015, the Member States of the UN included 'decent work for all' as part of SDG 8, including steps against 'forced labour, ... modern slavery ... (and) the worst forms of child labour' (SDG8.7), and set a target to '[p]rotect labour rights and promote safe and secure working environments for all workers, including migrant workers, in particular women migrants and those in precarious employment' (SDG 8.8).

Yet, despite international policy coordination and treaty obligations, our regulatory mapping of the hotspots also made clear that the risks to people and planet persist. Rates of extinction are between 10-100 times higher than is sustainable, if we are to retain biodiversity [10]; most workers in the electronics industry are non-unionised, employed on temporary contracts, and dying at alarming rates [20]; almost 50 million tonnes of electronic waste (e-waste) was generated globally in 2016, but only 20 per cent was recycled via appropriate channels. A small amount (4 per cent) was landfilled or incinerated. It is not known what happened with the remaining 76 per cent [21]. These are the manifestations of the 'wicked problems' mentioned above, problems that resist regulatory solutions in part by transgressing the usual boundaries of scientific disciplines or jurisdictions in law.

Our regulatory ecology analysis suggests four principal sources of this resistance. These arise from interactions that take place around each hotspot but that are also common to all three hotspots. These are:

- Regulatory Disjunctures arising from globalised production (offshoring and outsourcing); 
- Business Models that foster decision making that rewards regulatory arbitrage, evasion and avoidance with respect to sustainability regulation;

- Technology Design that promotes unsustainable production and consumption;

- Marginalisation of affected constituencies, which undermines the demand for enforcement.

\subsection{Regulatory Disjunctures}

There are international legal regimes which establish legal norms requiring the protection of people or the planet from the relevant harms. These clusters of international law each seek to regulate with respect to particular interests-for example, to protect biodiversity, or limit the impacts of the industrial use of chemicals. However, there are significant problems of either international law coverage of particular impacts, such as from mining or e-waste recycling, as well as with national implementation.

The problems of legal coverage for particular impacts are exemplified by the global regulatory approach to mining. Mining operations are regulated at the national level. There is no corresponding international law of mining. Instead, states have made international law that regulates with respect to various impacts that arise from activities, of which mining is one. The global frameworks for the protection of biodiversity, established by the CBD, do not mention specific impacts of particular industries. Thus, while the Aichi targets correspond to two important planetary boundaries affected by the mining of natural resources essential to the production of mobile phones-the reduction of habitat loss (Aichi Biodiversity Target 5) and the reduction of pollution (Aichi Biodiversity Target 8) -there is no specific mention of mining impacts on biodiversity. The clustering approach implied by the Aichi Target 8 reference to 'other international processes'-Stockholm Convention, Rotterdam Convention, Basel Convention-does not result in international law regulation which address the particular threats to biodiversity generated by mining. One treaty that does address mining directly is the Minamata Convention (2018), but it is concerned with one mineral only (gold), the impact of one chemical only (mercury) and is too new to assess in terms of effectiveness. This suggests that there is a significant gap in substantive law to adequately protect biodiversity from the effects of mining. This is alarming considering the apparent trend towards the increased demand for minerals that is implied by a transition towards electrification as a replacement for oil and gas. For example, in 2018, the price of cobalt, which is a key metal for use in lithium batteries, surged to $43 \mathrm{U} \$$ per pound, from $12 \mathrm{U} \$$ two years earlier, only to plunge again to $16 \mathrm{U} \$$ early 2019 , due primarily to anticipated supply crunch driven by a demand for electronic vehicles [22].

This problem of substantive law coverage is aggravated by the challenge of jurisdiction, which arises from the transnational nature of the mobile phone lifecycle. The bulk of mobile phone production takes place in Asia. China is the largest producer and exporter of mobile phones. Components are also made in the EU, Korea, Japan, India, Mexico, the Philippines, Singapore, Thailand, and the US. There are increasing investments in electronics production in Vietnam, Cambodia, Indonesia, Malaysia, and Myanmar. For example, Samsung now produces 50 per cent of its mobile phones in Vietnam. These patterns of investment and production are a product of the tendency, increasing since the 1970s, for lead firms to both 'outsource' and 'offshore' aspects of production. The fragmentation of value chains, resulting from the combination of offshoring and outsourcing, results in a corresponding fragmentation in enforcement-which is manifested in apparent local (national) regulatory failure or ineffectiveness. In short, the transnationalisation of production means that the legal regulation of the PLC is similarly fragmented.

Fragmentation matters to product regulation, because it is very common: no single jurisdiction regulates entire PLCs. This is, in part, because states typically do not regulate economic activities beyond their own borders. For example, while EU directives will apply in all Member States, and may enshrine progressive norms with respect to protecting biodiversity, workers or waste management, they will not govern mining activities of EU or other companies operating in non-EU countries. Despite a declared policy of a non-toxic environment or protection of biodiversity, the EU must rely on regulators in other countries to ensure that the metals mined abroad, and which are sold in the EU 
as components of mobile phones, have been mined in a manner that respects biodiversity. Similarly, the EU Biodiversity Strategy explicitly implements the CBD and in general 'aims to halt the loss of biodiversity and ecosystem services in the EU and help stop global biodiversity loss by 2020 '. But EU support to stop biodiversity loss abroad consists primarily of providing official development assistance (ODA) to help countries protect ecosystems. At the same time, EU regulation to stop the import of illegal timber and tracking illicit wildlife trade suffers from 'too little action [ ... ] taken regarding other commodities' [23,24].

Technology plays a central role in maintaining and managing disjunctures of jurisdiction and substantive law. For many years, ICTs have enabled the coordination of fragmented systems of production across global value chains and production networks spreads across different countries. Today, the rapid expansion of platform services is significantly expanding the existence of non-standard forms of employment, helping to embed structures of informality and duality in local economies in part by integrating those economies to global flows of commodities and value. Software applications take advantage of the spread of the smartphones to turn the 'reserve army of labour' into an algorithmically coordinated market of individual contractors. These workers benefit from improved access to micro-jobs and wage information, but bear all the risks associated with precarious work throughout the various phases of the product lifecycle [25]. In this way, platform work can be said to perpetuate the familiar problem of underemployment (lots of informal work, little remuneration, typical of, for example, street sellers), through a technological fix that undermines the labour contract. A similar pattern is developing with respect to the end of life of mobile phones, in which unregistered small importers and online sellers of second-hand phones are in effect short-circuiting laws providing for Extended Producer Responsibility (EPR): for example, online sellers put electronics onto the market in, for example, Ghana, but have no legal presence in the country and therefore avoid Ghanaian EPR obligations to remove e-waste from the market [26].

In addition to its legal, technological, and geographic dimensions, the disjuncture between the product lifecycle and the laws that govern it, is also expressed by social norms which govern considerations about the division of regulatory labour between the public and private spheres. A common assumption held amongst policy makers and business is that where business impacts occur, states will step in to regulate or remedy the harm. However, law can get in the way of even that minimal role of the state. Trade secrecy has been used as the legal basis to deny workers information about the toxic materials with which they work [27]. That commercial law can be used to contest and even prevent disclosure of information vital to the health of workers or the environment is an example of commercial law trumping fundamental labour or environmental protections. At one level, this is an all-too-common trade-off between protections afforded people and the planet under the law on the one hand, and the economic interests of business on the other. Those trade-offs are mediated by social and political interactions (e.g., lobbying, regulatory capture) which, by limiting regulation and enforcement, perpetuate the externalization by businesses of their impacts onto the lives and health of people or the planet. The sum total of those interactions is a system in which governments remain or are nominally responsible for the impacts of business, while workers or society at large pay the price.

It is important to recognise that these disjunctures are themselves made possible by legal interventions. For much of the past four decades, trade and investment laws, and national commercial law in general, has tended to de-regulate business activity and liberalise markets, promote regional economic integration and lower institutional barriers to capital movements. These enabling legal frameworks, combined with technological innovations, have made outsourcing and offshoring a reality of contemporary capitalism $[28,29]$. They determine the various geographies of global value chains. There is a growing practice of free trade agreements including provisions on the implementation of multilateral environmental agreements or minimum labour standards [30]. However, these are general clauses-not specified with respect to particular impacts, such as eco- and human toxicity from mining or manufacturing-and they are not always backed with domestic remedies or penalties. They must compete with demands for the maximization of value by shareholders, a demand that is in 
some jurisdictions enforceable in the courts. These fundamental disjunctures between production and consumption on the one hand, and the policies and laws meant to protect our social and environmental systems on the other, are evidence of the fact that unsustainability is in part a creation of law. The failure of regulation is not so much an absence of law or regulation as it is a particular regulatory mix that promotes or allows unsustainability to persist.

\subsection{Business Models}

Within the macro-level structures of the product lifecycle, companies make decisions about production and consumption. In the case of the mobile phone, the striking reality is sheer volume, as reflected in production numbers indicated in the introduction. Seen in isolation, these numbers suggest production is responding to an expanding demand for communications. However, business models are key to structuring that demand: most brands operate on business models and marketing strategies dedicated to increase the consumption of phones, often through encouraging the purchase of a new phone every year, or via de facto or 'planned obsolescence'. As described below (see Section 3.3 Technology Design), social entrepreneurs, such as Fairphone, have illustrated how it is possible to design smartphones with a view to extending its lifespan. Still, large brand producers continue to design phones that are hard to repair and to sell spare parts that are costly and only available for authorised repairers, all of which contributes to phones being treated as disposable.

In practice, the decisions of market actors around production are logical conclusions drawn by people who run companies on the basis of a series of constraints. The transnational nature of contemporary systems of production and consumption presents producers with choices about, for example, whether to make components internally or buy components from outsider sources or suppliers, and whether to purchase from suppliers domestically or abroad. Constraints include costs and prices, availability of skilled labour and technology, legal compliance with environmental or labour regulations, company values or goals, the demand of shareholders (if a public company), and the qualitative aspects of consumer demand, such as style or durability. For example, in the case of the mobile phone, these considerations have enabled electronics brands structure value chains in order to capture the lion's share of value [31]. The technological and legal frameworks of global trade and investment enable brand phone makers to arbitrage various risks—-such as labour, or disposal—between countries seeking to promote economic and social 'upgrading' [14].

One way of thinking about the processes involved in a firm reconciling these competing modes of constraint in the process of production is the concept of business models [32]. It is impossible to cover all business models here, but common to traditional business models are management economics concepts such as efficiency (the ratio of the actual output to the potential output) and productivity (narrowly defined as rate of output per unit input) and shareholder primacy (maximizing short-term returns to shareholders). These tend to be socially normative with respect to decision making by the managers of firms. As social norms within industry or firms, efficiency and productivity form the basic logic of managerial interactions with suppliers (i.e., cutting costs, ensuring quality), consumers (i.e., setting prices, developing brand loyalty). These are also the basis for meeting the targets expectations in terms of shareholders primacy, i.e., maximizing returns to shareholders [33]. In short, the drive for efficiency and productivity is normative in that it is presumed to be a good thing for business by the community of managers, owners, and shareholders, among others.

In this way, business models drive the search for factor inputs, such as natural resources or labour in manufacturing, that are low cost. This drive, combined with the regulatory disjunctures described above, manifests itself in the infamous race-to-the-bottom, defined as regulatory competition between jurisdictions over the least costly forms of regulation in order to attract investment or other forms of business activity. For example, in 2014-2015, wages for electronics workers in Hanoi, Vietnam, were less than half those of electronics workers in Shenzhen, China, which in turn were a mere 20 per cent of wages earned by workers in Japan. These data indicate that as wages have begun to increase in the coastal production regions in China, and as labour force preferences in those regions has 
shifted away from factory work, production has been shifted both inland (e.g., Foxconn, Zhengzhou), as well as off-shore, via new investment in low wages countries such as Vietnam, Myanmar, Cambodia, and Bangladesh [34]. This movement of production is an expression of shifting patterns of foreign direct investment, which tends to direct capital investment to locations where factor inputs, such as labour costs, are low. But it is also a product of the changing structure of manufacturing GVCs in Asia, including a tendency on the part of certain lead firms towards reliance on a smaller number of large suppliers, often in large emerging markets, where they can take advantage of a large supply of informal workers and capitalise on large domestic markets for their products [35].

The interaction of loose labour markets, legal frameworks that encourage transnational investment, and technology that enables the coordination of production across fragmented geographies of production ensure that electronics companies are able to demand flexibility from their workforce. The demand for flexibility translates into non-standard forms of employment that contributes to informality and dualism, which further increases the significant leverage of employers over workers [36]. The effect is to shift the costs of dangerous work or non-standard forms of employment onto workers, who are also vulnerable to downward pressure on wages [37].

An important facet of this interaction of business models with a regulatory race-to-the-bottom manifests itself in business decision making in the form of regulatory arbitrage, the practice of moving business operations to jurisdictions of least oversight or cost from regulation [38]. The economic incentive to exploit natural resources and rely on precarious work does not diminish when those resources or workers are located in vulnerable habitats or jurisdictions with poor labour protections; at least, not unless states impose costs, such as requirements that mining operations show they can avoid biodiversity losses or ensure decent work. However, states eager to attract foreign direct investment may not impose such costs: where the regulatory frameworks impose costs on business, for example, through labour and environmental regulation, states can compensate by a lack of enforcement. The causes of what is often perceived as a failure to regulate are different in each country. Common factors include an institutional incoherence concerning regulatory mandates (competing mandates), a lack of capacity in key institutions (e.g., in labour inspection, border controls or environmental oversight), or a combination of these. These weaknesses may also be a result of regulatory capture (of states) by industry, corruption, conflict or some combination of these [14,34].

\subsection{Technology Design}

The material or physical aspects of each phase of the production process act as a constraint on sustainability in that phase. The demand for minerals necessary in electronics production necessitates the intrusion of mining operations into areas of natural habitat to obtain the necessary ores as the basis for the manufacturing of phone components. Mining, both Artisanal and Small-scale Mining (ASM) and Large-Scale Mining (LSM), affects biodiversity through the removal and poisoning of those habitats.

The design of mobile phones reinforces business models and marketing strategies dedicated to increase the consumption of phones. Rather than seeking to prolong the life of the phone, design promotes consumption, often based on rapid advances in technology. The expectation of a new, fashionable phone every year creates what might be termed a form of consumer-driven 'planned obsolescence'. Social entrepreneurs, such as Fairphone, have illustrated how design (e.g., modularity, self-repair, and conservative materials use) is vital to lowering the overall impact of the mobile phone as a product, including by extending the mobile phone lifespan [39]. However, Fairphone is an exception. Large brand producers continue to design phones that are hard to repair and to sell spare parts that are costly and/or only available for authorised repairers. Regulations, such as the EU's Eco-design directive, do not constrain such practices as they do not apply to mobile phones [40].

Design also plays a central role in the use of hazardous materials in the manufacture of mobile phones. Printed Circuit Boards (PCBs) and chips both contain hazardous materials and the process of obtaining these at the extraction phase, as well as the process of handling them as waste, generate significant 
risks to people and the environment. In the manufacturing phase, the industrial processes involved in making PCBs and chips involve the use of hazardous chemicals, for example known carcinogens [41]. Information about toxicity in phones is not served by existing regulation. The EU's Registration, Evaluation, Authorisation, and Restriction of Chemicals (REACH) regulation addresses hazardous materials in a product but does not require producers to specify the location of those substances in the products (i.e., in what components), nor to identify any hazardous substances used in the production of a product abroad. This means that manufacturing and recycling workers have little basis on which to assess the risks of working with the components of mobile phones [42].

Limiting the toxicity impacts of electronics production has been a struggle for decades. While workers have won certain victories with respect to workplace health and safety in the production of mobile phones, the use of hazardous materials of mobile phones has gone largely unaddressed, other than to shift production to jurisdictions with less oversight and less labour power. In addition, the legal frameworks applicable to e-waste in the end of life of mobile phones are not designed to deal with the particular hotspot of eco-human toxicity. As noted above, electronic waste is the fastest growing waste stream. Extended Producer Responsibility (EPR) makes original equipment manufacturers responsible for reaching collection and recycling targets. This has increased rates of collection in countries with pre-existing recycling capacities. However, despite expressly seeking to do so, it has not prompted a change in product design [43]. They remove material from circulation and put small and medium sized repairers and recyclers at a disadvantage. In this way, EPR can counter-act circularity: it prioritises the removal of e-waste from the market, which may increase the demand for new products, rather than promoting repair and refurbishing as the basis for extending the life of existing products [44]. Secondly, there is a significant lack of clarity in the regulations between second-use electronics and e-waste, with the result that the regulation of transboundary end-of-life electronics tends to treat everything as waste. While this makes sense from a precautionary approach, it in fact undermines the attempts to extend the lifetime of mobile phones through repair and refurbishment, which often takes place across borders. For example, it restricts flows of second-use electronics to developing countries where informal repairers make those second-hand products available to local markets. Finally, it also fails to recognise the e-waste flows from developing countries constitute a supply of vital metals that, at present, are being collected informally and sold on to India and China [44-46].

\subsection{Marginalisation}

When labour markets are loose due to an abundance of workers, often living in poverty and with little in the way of social protection, the leverage of workers to protect themselves through, for example, various forms of collective action directed at employers or at governments is significantly reduced. This, in turn, makes low wage jurisdictions more attractive to investment $[47,48]$.

In all three hotspots examined-resource extraction, manufacturing, and end of life-labour market informality posed important problems to the effectiveness of regulation for sustainability. The presence of informality in the mining sector is an important obstacle to effective protection of biodiversity. In many cases it remains unclear what aspects of existing mining laws, environmental or social protections should apply to ASM and, where applicable, how those rules might be made effective. While informality may mean a passive attitude on the part of regulators, governments have also been known to clamp down in a repressive manner on artisanal mining, in effect criminalising the coping economies of households living in poverty. Often these two attitudes-passivity and repression-alternate $[49,50]$. In the manufacturing sector, the demand for flexibility in the labour market translates into non-standard forms of employment that contributes to informality and dualism, which further increases the significant leverage of employers over workers. The effect is to shift the costs of dangerous work or non-standard forms of employment onto workers, who also are vulnerable to downward pressure on wages [51].

A missing element in all three phases is a common, global approach to ensuring workers receive an improved share of the value they produce. The use of trade union networking and Global Framework 
Agreements to structure labour relations across the product lifecycle to promote both economic and social upgrading are underutilised. There are indications that industry due diligence standards that require certain minimum levels of responsible sourcing have had similar effects as the criminalisation of ASM by states, in that they in effect exclude ASM from global supply chains and thus negatively affect livelihoods. However, the evidence with respect to effectiveness and unintended harms remains anecdotal. In fact, there is a paucity of research into the effects of regulation on mining and biodiversity in general. There are calls for states and companies to respect freedom of association for workers, or channel development assistance to ASM collectives; however, there seems to be little in the way of active efforts by governments to consider what interventions might empower workers to secure a greater share of the value produced, or to consider how to make workers and their organisations central to the economic and social upgrading that will inevitably be required in the drive for sustainability.

This is a serious oversight. It is reminiscent of the marginalisation of indigenous peoples with respect to natural resource extraction. There have been increasing calls to recognize indigenous peoples as defenders of biodiversity, but the potential for empowerment of marginalized workers or indigenous peoples to reinforce regulatory efforts has yet to be seriously considered. Similarly, informality in repair and recycling is not factored into policy. Where it occurs in the form of artisanal repair and recycling, both in developing countries as well as through a growing community repair movement in many European countries, it is largely ignored or, as indicated above, undermined by existing regulation. Community repair promotes a culture of repair, enabling affordable repair and consumer self-repair. Denying these repairers as well as independent repair shops access to materials and spare parts is counter-intuitive in the current transition to a circular economy.

\section{Discussion}

The results of the regulatory ecology analysis of hotspots in the mobile phone lifecycle suggest that, for policy makers, there should be two main priorities to consider when developing policy and law concerning the sustainability of electronics: toxicity and precarious work. In each phase of the main phases of mobile phone lifecycle, we found risks to the environment and workers arising from toxicity and work insecurities. In each phase, these risks also overlap, such as when hazardous chemicals posed a threat to artisanal miners processing gold in Democratic Republic of Congo, to factory workers in the manufacturing of certain mobile phone components in China or Korea, or to artisanal e-waste workers in Ghana.

The regulatory disjunctures, business models, design decisions, and marginalisation that characterise the mobile phone lifecycle suggest the need for a regulatory strategy. When considering regulation for sustainability, the challenges to regulation posed by globalisation cannot be the end of the story. Rather, we should consider regulation as a system, one that generates compliance-or the lack thereof-as the result of specific dynamics of non-compliance, both global and local. There is not the space her to describe this strategy in detail. Further work is needed to determine the totality of such an approach. However, it is possible to point to possible regulatory innovations that might be included in a strategy to ensure the sustainability of electronic products.

The first regulatory innovation to consider is simply the idea of a regulatory strategy itself, based on the awareness that a variety of legal regimes, and clusters of different laws, will need to be taken into consideration. This may entail legal reforms to corporate purpose in order to address the incentives for shareholder primacy or regulatory arbitrage presently embedded in many business models [52]. It may involve requiring a transformation of product design, towards reparability and reuse, as the basis for circular economy $[16,43,53]$. It may involve addressing marginalisation by empowering workers through the integration of Global Framework Agreements (GFAs) to trade agreements or worker-led monitoring to public procurement rules or domestic mandatory due diligence laws [54]. It may involve extending the possibility for communities or workers affected by toxicity in mining, manufacturing or e-waste sites to hold lead firms responsible in the courts of countries of third-parties directly harmed by manufacturing processes [55]. Second, any strategy should address sustainability as systemic, 
encompassing both social foundations and planetary boundaries as well as the entire product lifecycle. As such, the strategy will need to be differentiated by particular hotspots along the lifecycle. One way to think of this is to design regulation as interventions, legal measures that seek to intervene in the regulatory ecologies at work in particular hotspots, as opposed to relying on regulation that is directed at discreet social or environmental impacts.

New rules must respond to the glaring absence of harmonised, global protections against toxicity and labour insecurities in mining, manufacturing, and at the end of life of electronics. But policy makers should not wait for international agreement before taking action. Rather, a regulatory strategy should start at home, focused on products produced globally, but sold domestically. It is time to seriously consider whether borders that are open to trade should remain open to products that are the result of production processes which rely on precarious work or toxic impacts on people and planet.

Author Contributions: M.B.T. is responsible for conceptualisation, analysis, and writing (original draft, review, and editing). M.v.d.V. is responsible for data collection and writing (original draft, review, and editing).

Funding: This research was funded by the European Union under the Horizon 2020 programme, grant agreement 693642. The contents of this article are the sole responsibility of the authors and do not necessarily reflect the views of the European Union. The APC was funded by MDPI.

Acknowledgments: The authors wish to thank anonymous reviewers for their comments on the original draft, as well as partners and stakeholders in the research conducted under Work Package 4 of the Sustainable Market Actors and Responsible Trade (SMART).

Conflicts of Interest: The authors declare no conflict of interest.

\section{References}

1. GSMA Intelligence. Available online: https://www.gsmaintelligence.com/ (accessed on 1 October 2019).

2. Smartphone Woes Continue with Worldwide Shipments Down $4.9 \%$ in the Holiday Quarter Capping off the Worst Year Ever, According to IDC. IDC: The premier global market intelligence company. Available online: https://www.idc.com/getdoc.jsp?containerId=prUS44826119 (accessed on 2 October 2019).

3. Velden, M.v.d.; Taylor, M.B. Sustainability Hotspots Analysis of the Mobile Phone Lifecycle; University of Oslo/Fafo Research Foundation: Oslo, Norway, 2017.

4. Sonter, L.J.; Ali, S.H.; Watson, J.E.M. Mining and biodiversity: Key issues and research needs in conservation science. Proc. Biol. Sci. 1892, 285. [CrossRef] [PubMed]

5. Miller, K.A.; Thompson, K.F.; Johnston, P.; Santillo, D. An Overview of Seabed Mining Including the Current State of Development, Environmental Impacts, and Knowledge Gaps. Front. Mar. Sci. 2018, 4. [CrossRef]

6. Amnesty International. Time to Recharge: Corporate Action and Inaction to Tackle Abuses in the Cobalt Supply Chain; Amnesty International: London, UK, 2017.

7. Barthel, M.; Fava, J.; James, K.; Khan, S. Hotspots Analysis: An Overarching Methodological Framework and Guidance for Product and Sector Level Application; United Nations Environment Programme: Paris, France, 2017.

8. Bienge, K.; von Geibler, J.; Lettenmeier, M. Sustainability Hot Spot Analysis: A Streamlined Life Cycle Assessment towards Sustainable Food Chains. In Proceedings of the 9th European IFSA Symposium, Vienna, Austria, 4-7 July 2010; Available online: http://ifsa.boku.ac.at/cms/fileadmin/Proceeding2010/2010_WS4.4_ Bienge.pdf (accessed on 20 March 2015).

9. Velden, M.v.d.; Taylor, M.B.; Oteng-Obabio, M. Regulatory Ecology of Hot Spots in the Mobile Phone Life Cycle; University of Oslo, University of Ghana, Fafo Research Foundation: Oslo, Norway, 2019.

10. Rockström, J.; Steffen, W.; Noone, K.; Persson, Å.; Chapin, F.S., III; Lambin, E.; Lenton, T.M.; Scheffer, M.; Folke, C.; Schellnhuber, H.; et al. Planetary boundaries: Exploring the safe operating space for humanity. Ecol. Soc. 2009, 14, 32.

11. Steffen, W.; Richardson, K.; Rockström, J.; Cornell, S.E.; Fetzer, I.; Bennett, E.M.; Biggs, R.; Carpenter, S.R.; de Vries, W.; de Wit, C.A.; et al. Planetary boundaries: Guiding human development on a changing planet. Science 2015, 347, 1259855. [CrossRef] [PubMed]

12. Raworth, K. Doughnut Economics: Seven Ways to Think Like a 21st-Century Economist; Chelsea Green Publishing: White River Junction, VT, USA, 2017. 
13. Randers, J.; Rockström, J.; Stoknes, P.E.; Golüke, U.; Collste, D.; Cornell, S. Transformation is Feasible-How to Achieve the Sustainable Development Goals within Planetary Boundaries, A Report to the Club of Rome; Stockholm Resilience Centre: Stockholm, Sweden, 2018.

14. Locke, R.M. The Promise and Limits of Private Power: Promoting Labor Standards in a Global Economy; Cambridge University Press: Cambridge, UK, 2013.

15. Velden, M.v.d. Thinking with Care: Exploring Interdisciplinarity in a Global Research Project; SMART project; University of Oslo: Oslo, Norway, 2019.

16. Velden, M.v.d. Design as Regulation: Opportunities and Limitations for Sustainable Mobile Phone Design. In Culture, Technology, Communication: Common world, different futures; Abdelnour-Nocera, J., Strano, M., Ess, C., Velden, M.v.d., Hrachovec, H., Eds.; Springer: Cham, Switzerland, 2016; pp. 32-54.

17. Sjåfjell, B.; Taylor, M.B. Planetary Boundaries and Company Law: Towards a Regulatory Ecology of Corporate Sustainability. Unit. Oslo Fac. Law Res. 2015, 11, 1-33. [CrossRef]

18. Lessig, L. The New Chicago School. J. Leg. Stud. 1998, 27, 661-691. [CrossRef]

19. Benschop, Y.; Verloo, M. Gender Change, Organizational Change, and Gender Equality Strategies. In Handbook of Gender, Work and Organization; Jeanes, E., Knights, D., Martin, P.M., Eds.; Wiley-Blackwell: Hoboken, NJ, USA, 2012; pp. 277-290.

20. United Nations Human Rights Council. Report of the Special Rapporteur on the Implications for Human Rights of the Environmentally Sound Management and Disposal of Hazardous Substances and Wastes; United Nations General Assembly: New York, NY, USA, 2018.

21. Baldé, C.P.; Forti, V.; Gray, V.; Kuehr, R.; Stegmann, P. The Global E-waste Monitor 2017: Quantities, Flows, and Resources; United Nations University: Bonn, Germany, 2018.

22. Burton, M. How the Cobalt Market Fell Victim to Allure of Electric Cars. CCEX. Available online: https: //theccex.com/how-the-cobalt-market-fell-victim-to-allure-of-electric-cars/ (accessed on 19 September 2019).

23. Report from the Commission to the European Parliament and the Council, The Mid-Term Review of the EU Biodiversity Strategy to 2020; European Commission: Brussels, Belgium, 2015; COM/2015/0478 final.

24. Study for the Strategy for a Non-Toxic Environment of the 7th Environment Action Programme, Final Report, Written by Milieu Ltd, Ökopol, Risk \& Policy Analysts (RPA) and RIVM.; European Commission: Brussels, Belgium, 2017.

25. Jesnes, K. Employment Models of Platform Companies in Norway: A Distinctive Approach? Nord. J. Work. Life Stud. 2019, 9. [CrossRef]

26. Hilton, M.; Sherrington, C.; McCarthy, A.; Börkey, P. Extended Producer Responsibility (EPR) and the Impact of Online Sales; OECD: Paris, France, 2019; Volume 142.

27. Wigham, N. Korean Government cited 'trade secrets' to allow Samsung to conceal data from sick workers. News.Com.Au. Available online: https://www.news.com.au/technology/korean-government-cited-trade-secretsto-allow-samsung-to-conceal-data-from-sick-workers/news-story/719a058a6c68a3d7882b4107ae78dd89 (accessed on 19 September 2019).

28. Gereffi, G.; Humphrey, J.; Sturgeon, T. The governance of global value chains. Rev. Int. Political Econ. 2005, 12, 78-104. [CrossRef]

29. Jennifer, B. Global Capitalism and Commodity Chains: Looking Back, Going Forward. Compet. Chang. 2005, 9, 153-180.

30. Gammage, C.; Novitz, T. (Eds.) Sustainable Trade, Investment and Finance: Toward Responsible and Coherent Regulatory Frameworks; Edward Elgar Publishing: Cheltenham, UK, 2019.

31. Ali-Yrkkö, J.; Rouvinen, P.; Seppälä, T.; Ylä-Anttila, P. Who Captures Value in Global Supply Chains? Case Nokia N95 Smartphone. J. Ind. Compet. Trade 2011, 11, 263-278. [CrossRef]

32. Wells, P.E. Business Models for Sustainability; Edward Elgar Publishing Limited: Cheltenham, UK, 2013.

33. Sjåfjell, B. Capitalism, the Sustainability Crisis and the Limitations of Current Business Governance. In Company Law and Sustainability: Legal Barriers and Opportunities; Sjåfjell, B., Richardson, B.J., Eds.; Cambridge University Press: Cambridge, UK, 2015.

34. Lee, J.; Gereffi, G.; Lee, S.-H. Social Upgrading in Mobile Phone GVCs: Firm-level Comparisons of Working Conditions and Labour Rights. In Labour in Global Value Chains in Asia, 1st ed.; Nathan, D., Tewari, M., Sarkar, S., Eds.; Cambridge University Press: Cambridge, UK, 2016; pp. 315-352.

35. Nathan, D.; Tewari, M.; Sarkar, S. Labour in Global Value Chains in Asia; Cambridge University Press: Cambridge, UK, 2016. 
36. Precarious Work in the Asica-Pacific Region; ITUC and ITUC Asia: Brussels, Belgium, 2014.

37. Asia Monitor Resource Centre. Labour Rights in High Tech Electronics: Case Studies of Workers' Struggles in Samsung Electronics and its Asian Suppliers; AMRC: Hong Kong, China, 2013.

38. Yang, C. Relocating labour-intensive manufacturing firms from China to Southeast Asia: A preliminary investigation. Bdg. J. Glob. South 2016, 3, 3. [CrossRef]

39. Chen, Y.; Chen, M.; Li, Y.; Wang, B.; Chen, S.; Xu, Z. Impact of technological innovation and regulation development on e-waste toxicity: A case study of waste mobile phones. Sci. Rep. 2018, 8, 7100. [CrossRef] [PubMed]

40. Judl, J.; Tilkanen, J.; Riddlestone, S.; Rubbens, C. Creating Sustainable Smartphones: Scaling up best practice to achieve SDG 12; Bioregionale: Syke, UK, 2017; p. 35.

41. Chen, M.; Ogunseitan, O.A.; Wang, J.; Chen, H.; Wang, B.; Chen, S. Evolution of electronic waste toxicity: Trends in innovation and regulation. Environ. Int. 2016, 89-90, 147-154. [CrossRef] [PubMed]

42. GoodElectronics and ICRT. Challenge to the Global Electronics Industry: Make the Production Process Safer and Prevent Illness and Cancer from Dangerous Chemicals; GoodElectronics: Amsterdam, The Netherlands, 2015.

43. Yu, J.; Hills, P.; Welford, R. Extended producer responsibility and eco-design changes: Perspectives from China. Corp. Soc. Responsib. Environ. Manag. 2008, 15, 111-124. [CrossRef]

44. Oteng-Ababio, M.; van der Velden, M. 'Welcome to Sodom'-Six myths about electronic waste in Agbogbloshie, Ghana. Blogging Sustain. 2019, 3, 33.

45. Ardi, R.; Leisten, R. Assessing the role of informal sector in WEEE management systems: A System Dynamics approach. Waste Manag. 2016, 57, 3-16. [CrossRef]

46. Grant, R.J.; Oteng-Ababio, M. The Global Transformation of Materials and the Emergence of Informal Urban Mining in Accra, Ghana. Afr. Today 2016, 62, 2-20. [CrossRef]

47. Becker, K.F. The Informal Economy; SIDA: Stockholm, Sweden, 2004; p. 76.

48. Benanav, A. The origins of informality: The ILO at the limit of the concept of unemployment. J. Glob. Hist. 2019, 14, 107-125. [CrossRef]

49. Dorner, U.; Franken, G.; Liedtke, M.; Sievers, H. Artisanal and Small-Scale Mining (ASM). Polinaris Working Paper 19, Polinaris. Available online: http://pratclif.com/2015/mines-ressources/polinares/chapter7.pdf (accessed on 19 September 2019).

50. Corpus, T.J.; David, C.P.; Murao, S.; Maglambayan, V. Small-scale Gold Mining in the Ambalanga Catchment, Philippines: Its Control on Mercury Methylation in Stream Sediments. Int. J. Environ. Sci. 2010, $2,2$.

51. Drahokoupil, J.; Andrijasevic, R.; Sacchetto, D.; European Trade Union Institute. Flexible Workforces and Low Profit Margins: Electronics Assembly Between Europe and China; European Trade Union Institute: Brussels, Belgium, 2016.

52. Sjåfjell, B.; Taylor, M.B. A Clash of Norms: Shareholder Primacy vs. Sustainable Corporate Purpose. Int. Comp. Corp. Law J. 2019, 13, 40-66. [CrossRef]

53. van der Velden, M.; Taylor, M.B.; Oteng-Ababio, M. Sustainable product lifecycles: A systemic approach to the regulation of e-waste. In Proceedings of the 3rd PLATE 2019 Conference, Berlin, Germany, 18-20 September 2019.

54. Outhwaite, O.; Martin-Ortega, O. Worker-driven monitoring-Redefining supply chain monitoring to improve labour rights in global supply chains. Compet. Chang. 2019, 23, 378-396. [CrossRef]

55. Salminen, J. From product liability to production liability: Modelling a response to the liability deficit of global value chains on historical transformations of production. Compet. Chang. 2019, 23, 420-438. [CrossRef]

(C) 2019 by the authors. Licensee MDPI, Basel, Switzerland. This article is an open access article distributed under the terms and conditions of the Creative Commons Attribution (CC BY) license (http://creativecommons.org/licenses/by/4.0/). 